\title{
A SOCIOLINGUISTIC ANALYSIS OF VERBAL GREETINGS, ADDRESS FORMS AND PARALINGUISTIC BEHAVIOURS IN KISUBI
}

\author{
Ibrahim D. Rwakakindo \\ University of Dodoma \\ rwaka1974@gmail.com
}

\begin{abstract}
This paper analyses the greeting system of Kisubi. It specifically seeks: to identify temporal greeting patterns in Kisubi; to determine whether age and gender do dictate the kind of verbal greetings, address forms and paralinguistic behaviours that are used in particular greeting events; to examine different kinship-specific verbal greetings, address forms and paralinguistic behaviours that are used in particular greeting events; and lastly, to assess the role of context in the Kisubi greeting system. Observation and face-to-face interview methods were used to gather data from 36 participants who were obtained using snowball sampling technique, and afterwards they were stratified into different strata depending on age, gender and educational status of a person. This stratification led to the attainment of authentic data. The obtained data were subjected to content analysis from which different themes emerged. It was established that there are four temporal chunks in Kisubi, each of which is associated with its own greeting term. Age, gender, context and kinship relations also determine the type of greeting terms and the honorifics or deferential terms to use. However, the use of honorifics and/or deferential terms is declining gradually.
\end{abstract}

Key words: genuflecting, squatting, paralinguistic behaviour, greetings, honorifics, gender, age, Kisubi, Subi

\section{Introduction}

Kisubi is a Bantu language indigenously spoken in Biharamulo district, Kagera region, Tanzania. Its speakers are approximately 135,479 (Rugemalira \& Muzale 2008). It certainly belongs to the Rutara branch of the Lucustrine languages (Kihaya, Kinyambo, Kizinza, Kinyankole, 
Kitooro, Kichiga, Kinyooro, etc.) because it exhibits greater lexicosemantic similarity with the languages in the branch. Apart from this brief description of Kisubi, it is worth conceiving the term "greetings" in its generality.

Greetings can be conceived of as obligatory conventionalized linguistic expressions of knowing one's welfare, wishing somebody the best of luck, initiating conversation and/or relationship between one person and another, showing age or status difference between two people, or showing that people belong to the same age group, or are relatively of the same age despite the subtle age difference between them, and/or showing kinship relationship - they are generally formulaic linguistic and non-linguistic expressions in a human society (Sommer \& Lupapula 2012). Greeting one another in an appropriate manner and context of situation is a social norm that should be adhered to by every member of society. However, some forms of greetings across African cultures are relatively obsolete due to education and urbanization.

In Bantu societies, greetings are structured in such a way that they reflect the hierarchical structure of society (Sommer \& Lupapula 2012). The society is stratified; hence, greetings have to map onto these strata. One thing to note is that, in the interactional discourse, verbal and non-verbal linguistic behaviours do largely go concurrently. In this paper, non-verbal linguistic behaviours have been referred to as paralinguistic behaviours, some of which include squatting, genuflecting, spatial distance between interlocutors, head-nodding, hand shaking and embracing.

Some cross-cultural studies on greetings and their associated forms of address have already been conducted (see, for example, Weinrich 1982). However, it is evident that actual greetings are usually preceded by pre-linguistics (pre-greeting formulaic expressions). For example, Sommer \& Lupapula (2012) are of the argument that in Kihaya and Kikerewe, pre-greetings are inescapable and do differ according to different socio-cultural parameters, namely seniority, age, gender and kinship relations. 
However, it is worth arguing that most Bantu societies have homogeneous social structures but heterogeneous forms of greetings and their embedded cultural semantics (Akindele 2007). Hence, it is much better to study an individual speech community in isolation in order to uncover greeting patterns, address forms and paralinguistic behaviours. It is this fact that forms an angle of departure into analysing greetings, address forms and paralinguistic behaviours in Kisubi. Specifically, this paper has been structured on the basis of the following objectives: to identify temporal greetings in Kisubi; to determine whether age and gender do dictate the kind of verbal greetings, address forms, and paralinguistic behaviours that are used in the Kisubi greeting system; to examine different kinship-specific verbal greetings, address forms and paralinguistic behaviours that are used in the Kisubi greeting system; and lastly, to assess the role of context in the Kisubi greeting system.

\section{Literature review}

\subsection{Theoretical literature review}

Greetings require the interaction of two people or a person with a group of people. In such an interaction, every interactant is expected to display a certain acceptable behaviour (linguistic or non-linguistic) that may mutually necessitate fruitful occurrence of the greeting event. In other words, interlocutors need to display polite linguistic and non-linguistic behaviours, as well as requisite pragmatic competence of the greeting event. For example, when, how, where and to whom should a certain greeting term be used; and what duration of time should be used in such a greeting event. Moreover, physically, how should each interactant appear; and how does each interactant expect to be treated in such a greeting event. Generally, each interactant would like to protect his/her face (image) by displaying requisite politeness. This takes us to the need to throw light to the politeness theory by Brown \& Levinson (1987) and its parent theory, the face theory, by Goffman (1955); and other scholars who have ventured into describing and prescribing 
people's interactional/conversational structure, focusing on the key principles underlying such a conversational discourse.

In Goffman's (1955) face theory, face is defined as the positive public image you seek to establish in social interactions: the way you desire to be before others or the way you would like the public to consider you to be, e.g. to be kind, to be intelligent, to be inquisitive, to be generous, to be caring, to be daring, etc. However, Brown \& Levinson (1987) - in the politeness theory - have extended the face theory by arguing that there are two categories of face: positive face and negative face. On the one hand, positive face is the desire for approval and acceptance by others; but on the other hand, negative face is the desire to proceed without being impeded upon. In this regard, approval is reflected in the way other people respond to us - showing respect and honour; and acceptance is reflected in the way other people evaluate us in terms of our usefulness, contribution, achievement and behaviour. For example, in the greeting domain, some greetings are advanced to some people according to their socio-economic status in the society as a way of honouring, recognising and appreciating their achievements and/or contributions (the age factor in this regard is eclipsed, i.e. it is bypassed and/or not considered). That is why a small-aged person may be greeted, in the most respectful way, by an old-aged person. In this context, what is being greeted is not age but tremendous socio-economic achievement made by that person.

It goes without saying that the precursors of the politeness theory viewed politeness as a universal concept, and participants in an interaction have to see to it that they avoid causing discomfort or embarrassment to the collocutors. While the basic idea of "face" remains unchallenged, the argument that realisation of politeness is universal has been overtly criticized and has led to some conceptual modifications (Mapunda 2017). Mills (2011) as cited from Mapunda (2017) argues that in different cultures, politeness can be realized in different ways based on different values and premises, and has different functions other than protecting face. As an example, she mentions discernment of individuals as an expression of politeness in specific contexts so that they are addressed 
and treated accordingly. The notion of "discernment" was initially provided by the pragmatician Ide (1989) who brought up this notion as a critique to universality of the politeness model proposed by Brown and Levinson (1987). Ide's main argument has been that in Japanese culture, honorifics are used strategically as a marker of politeness.

Moreover, Lackoff (1975) argues that there are many types of behaviour that can be called "polite". She characterizes some forms of politeness as linguistic, some as non-linguistic and some as mixed. Different forms may be regarded as polite in some settings and impolite in others; some as neutral and some as downright rude. As such, she proposes three "universal rules" for politeness, which are not mutually exclusive: formality (the need to keep aloof); deference (the need to give options using different ways such as euphemisms, hedges, etc.); and camaraderie (which is the necessity to show sympathy). As it can be seen, these different postulations point to the need for specificity in studying politeness in different cultures since universality cannot cut across the board.

Another scholar who has convincingly argued towards a more balanced understanding of politeness seems to be Haugh (2013). In his study on evaluations of (im)politeness as a form of social practice, he has argued that despite all the criticisms leveled against the study of "face-work", politeness is still evaluated with regard to face-work and norms as evaluated by participants. In a way, this is to say that the need to protect the face of the collocutors is still prominent even in the proposed replacements.

In view of different theoretical orientations of scholars on politeness and its embedded diverse socio-cultural elements, it is worth articulating that: since greeting is a socio-cultural phenomenon which requires some formulaic linguistic expressions and/or behaviours (verbal and nonverbal) to be performed in a manner that may not cause discomfort or embarrassment to either party in the actual greeting event, and since there are many forms of behaviours that can be called "polite" (which differ from one culture to another), it follows therefore that this study embraced Lakoff's (1975) theoretical orientation. 


\subsection{Empirical literature review}

In this section, a brief literature review will be done. To start with, greetings are viewed as: the exchange of expressions, pleasantries, or good wishes between two people or a group interacting for the purpose of fulfilling social obligations or for the purposes of establishing interpersonal relationship; extremely important strategies for the negotiation and control of social identity and social relationships between participants in a conversation; a set of linguistic and nonlinguistic devices used for the initial management of encounters; means of establishing identity and affirm solidarity, and do constitute a necessary stage on the route to "interpersonal access" whereby information can be sought and shared; the essential "oil" of encounters of all types and a reassuring confirmation of human sociability and social order; and formulas which universally serve an affective function of establishing non-threatening contact and rapport, but their precise content is clearly culture-specific (Akindele 2007; Laver 1981; Youssouf et al. 1976; Emery 2000; Schottman 1995; Holmes 1992).

Similarly, Akindele $(1990 ; 2007)$ argues that greetings may either be prefatory, informatory, pre-closing or closing. Prefatory greetings are content-void. In the wolf greeting system, they are referred to as passing greetings (Irvine 1974).They are casual greetings which usually prelude or pave way for the content greetings (informatory greetings). They are also conceived of as in-a-hurry greetings. Examples from English include hi, hello, etc. On the other hand, informatory greetings are content-oriented. Examples from English include: How are your children? Along the same vein, pre-closing greetings usually mark the end of informatory greetings. They are sometimes called pre-departing greetings. An example from English include: Give my warm greetings to your family. In contrast, closing greetings do mark the end of the interaction. An example from English include: goodbye. Generally, the four types of greetings seem to be universal cross-culturally.

However, every speech community has got specific categories of greetings related to age, gender, kinship relations and socio-cultural events (see, for example, Elegbeleye 2005; Schleicher 2010; Odebunmi 
2013). Similarly, in some communities, greetings are accompanied with certain deferential terms and paralinguistic behaviours (see, for example, Yusuf 1973; 1979; Oumarou 1997).

However, other greeting terms have been over-ridden by certain terms from other languages, usually languages of the immediate community. This is affirmed by Mapunda (2017) who argues that in the past, when greeting father or mother, one could respectfully say tukuwoni dadi / mawu 'good morning father/mother'. Nowadays, such a greeting style has been replaced by the Swahili style: shikamoo baba / mama 'good morning father/mother'. Presumably, this is due to the interplay of many factors, the fundamental ones being: a greater value attached to Kiswahili as a language of the immediate community, urbanization, education, or the regular use of Kiswahili especially by young people.

In Kisubi, there is no any ethnographic study on greetings that has so far been conducted with exception of two studies that have been done on Kisubi. The first study was done by Nkumbulwa (2015) and it was on the collection of the Subi proverbs, and the second study was done by the author of this article - the Ph.D. thesis (Rwakakindo 2019) - and it was on the morphosyntactic and semantic analysis of possessive noun phrases in Kisubi. Since there is no any ethnographic study on greetings that has already been conducted in Kisubi, it follows therefore that this is an inherent knowledge gap which this study attempted to bridge.

\section{Methodology}

This study was done qualitatively with minimal quantificational elements. It was conducted in Biharamulo district, in Kagera region, where Kisubi is indigenously spoken. Data were collected through personal observation and face-to-face open-ended semi-structured interview using a stratified sample of 36 respondents, distributed proportionally in terms of gender and educational backgrounds. Hence, the sample had these categories of respondents: three (3) uneducated old women, three (3) less educated old women, three (3) educated old 
women, three (3) uneducated young women, three (3) less educated young women and three (3) educated young women. Even male respondents were in categories of this nature, thus making a sample size of 36 respondents. The age of old women/men ranged between 45 and above, whereas the age of young women/men ranged between 18 and 44. In the context of this study, uneducated old/young women and men refer to those who did not go to school at all or went to school but could not read and write; less educated old/young women and men were those with primary education and could write and read; and educated old/young women and men had secondary and tertiary education. In order to get respondents in each category, snowball sampling $^{1}$ and stratified sampling ${ }^{2}$ techniques were employed. The question of education was thought of in order to see whether it had any impact on the greeting system in Kisubi.

In gathering data using face-to-face interview, the responses were audio-recorded for later retrieval during transcription and subsequent thematization; and during observation in different greeting discourses, the observable facts were noted in the field note-book. It therefore follows that since all data were virtually qualitative, analysis was done thematically - content analysis was done and themes were established basing on the objectives of the study.

\section{Results and Discussion}

\subsection{Temporal Greetings in Kisubi}

On the one hand, greetings are time-determined socio-cultural phenomena: time segments of the day do determine a particular type

${ }^{1}$ It is mainly used when the researcher does not know who in the target population is informative enough to yield requisite information. Hence, each respondent refers the researcher to another respondent with the required information.

${ }^{2}$ It is mainly used when the target population is in strata and the study naturally dictates that each stratum should be represented in the study in order to get a holistic picture of the phenomenon under investigation. 
of greeting to be used. In Kisubi, the greeting system maps onto different categories of hours, namely morning hours, afternoon hours, evening hours and bedtime hours. Each category of hours is associated with a particular greeting term, which is also associated with particular socio-cultural behaviours. In the morning hours, the usual greeting is sura and its response depends on the age/relation status of the greetee (details are in the subsequent sections). It may be affixed with words depending on the status or kinship relation between the interlocutors. For example, brothers-in-law usually greet each other surawaitu, literally meaning "I greet you". In this greeting, the italicized element is an affix co-occurring with the stem sura. The greeting sura may feature also during past morning hours provided that the interlocutors did not meet in the morning and/or they have not met for some days. It may optionally be followed by a variety of honorific terms depending on the relation status of the interlocutors.

In the afternoon hours, the greeting term used is mwasibha which is a clipped word from a word mwasibhage 'have you been well'. The response to this greeting depends on the age/relation of the greetee. If the interlocutors are sisters-in-law, the response remains the same (mwasibha / mwasibha); and if there is an age gap, the greetee responds wasibhoota 'how have you been', which is a blend of two words: $w a s i b h a+o t a$. The greeting may optionally be followed by honorific or deferential terms depending on the nature of the interactants (details are in the subsequent sections).

From evening through bed time, interactants greet each other wasibhoota 'how have you been'; and during bed time, interactants usually adieu each other using age/relation specific terms - in this regard are referred to as ways of parting/leave-taking (cf. Akindele 2007). For youngsters, they simply adieu each other mpaho 'goodbye'; for sisters-in-law and women of relatively the same age, they adieu each other muragabha 'goodbye'; for males who are about to marry, they reciprocally adieu each other orasingawaitu 'goodbye' (this greeting is also used by brothers-in-law and married men of relatively 
the same age); for males with a greater age range, the young utter orasingawaitu / muragabha 'goodbye' and the old reply oralege / muralege 'sleep well'; for a brother-in-law and a sister-in-law, the former utters orasingawaitu 'goodbye' and the latter replies muragabha 'goodbye'; for a male and female who are relatively of the same age, they reciprocally adieu each other oralege 'sleep well'; and for a male and female whose age range is not too big, one utters oralege 'sleep well' and the other replies oralekuzima 'sleep well too'.

Generally, the greeting system in Kisubi is in transition. Interactants are more often found skipping the afternoon greeting and opting for the usual evening greeting, wasibhoota, which is usually regarded as a neutral greeting term for the fact that it eclipses the age factor.

\subsection{Age-specific verbal greetings, address forms and paralinguistic behaviours}

4.2.1. Greetings between males and females of relatively the same age or whose age difference is assumingly

to be not greater than five years

If two men meet, either of them initiates the greetings. Normally, pregreetings precede the actual greetings (cf. Youssouf et al. 1976; Emery 2000; Akindele 2007). The initiator may utter any of the pre-greeting terms, such as otamwoozo 'how are you boy/man', nigahi 'what's up', etc. followed by surawaitu 'I greet you'. Then, the initiatee responds in the same way. In most cases, surawaitu is accompanied with handshaking. In some instances, it is accompanied with a honorific/ deferential/affectionate term like mweneso / chombeka, 'friend/the builder', and then handshaking.

For women, different greeting patterns and social behaviours are observable. In the interactional discourse, either of the interlocutors may initiate the greetings: usually pre-greetings followed by the actual greeting. The commonly used pre-greetings include: ota 'how are you?' and the co-interlocutor responds maahi 'nothing', and agaraileyo / agaliyo 'what's up there?' and the response is tuliyo 'we are fine'. The 
pre-greeting term is followed by the actual greeting, sura 'good morning', and the co-interlocutor responds in the same way. The greeting is optionally accompanied with genuflecting on one knee for both interlocutors.

In the interactional discourse where a man and a woman meet, either of them may initiate greetings. The actual greeting is railota 'how have you slept'. The initiator utters railota and the initiatee responds in the same way provided it is in the morning or at any time of their encounter on condition that they have not yet met since morning. From the afternoon through evening up to bed time, the normal greeting is wasibhoota and the greetee responds in the same way.

The greeting term, railota, is optionally followed by handshaking and genuflecting (a woman genuflects). In most cases, the interlocutors do not come closer unless they are socially motivated to do so. Boys and girls, especially those of tender age, do not have a ritualized greeting system; they casually greet each other using any silencebreaking word like zimpe 'give me the news'.

\subsubsection{Greetings between males and females with a relatively greater range of age}

(six years and above)

Young men greet old men first by uttering sura or surawaitu 'good morning' or 'I greet you' and the greetee, who is usually not too old, responds railege / railota 'have you slept well / how have you slept'. This is usually the morning greeting or the greeting for the interlocutors who have not met since morning, or who have not met for some days. Such a greeting is optionally followed by handshaking. If it is in the afternoon and they have already met in the morning, the usual greeting is mwasibha 'have you been well' and the greetee responds by saying wasibhoota 'how have you been'. From the evening through bed time, the interlocutors greet each other wasibhoota 'how have you been', but the initiator being the young man. The same greeting may take a somewhat different form if uttered to men who are too old $-50+$ years. 
The honorific/deferential label is usually added at the end of the greeting, thus: sura mzee / surawaitu mzee 'good morning old person' or 'I greet you old person', and the greetee responds railege/railota 'have you slept well / how have you slept'. The word mzee 'old person' connotes respect or deference. If it is in the afternoon and they have already met in the morning, the usual greeting is mwasibha mzee 'have you been well' and the greetee responds wasibhoota 'how have you been'. From evening through bed time, the usual greeting is wasibhoota mzee 'how have you been old person' and the greetee replies wasibhoota 'how have you been'.

When young men greet women who are not too old, the usual greeting is sura 'good morning' and the greetee replies railege / railota 'have you slept well / how have you slept'. This applies in the morning or in the afternoon through evening provided the interlocutors have not yet met since morning or they have not met for quite some days. In the afternoon, the greeting is mwasibha 'have you been well' and the greetee (the woman) replies wasibhoota 'how have you been'. From evening through bed time, the interlocutors greet each other wasibhoota, the initiator being the young man. In contrast, if a young man greets a woman who is too old, the honorific/deferential marker mkaire 'old woman' is added to the usual greetings of the day; thus, sura mkaire 'good morning old woman' (if it is in the morning or at any time of their encounter provided they have not yet met in the morning) and she replies railege / railota 'have you slept well / how have you slept'. If it is in the afternoon, the young man utters mwasibha mkaire 'have you been well old woman' and the greetee replies wasibhoota how have you been'. From evening through bed time, the old woman is greeted wasibhoota mkaire 'how have you been old woman' and she replies wasibhoota 'how have you been'. Moreover, if a young woman greets an old man (whether not too old or too old), she has to genuflect on one knee and utter sura 'good morning' (in the morning), mwasibha 'have you been well' (in the afternoon) and wasibhoota 'how have you been' (in the evening through bed time). 
In other sociolinguistic scenarios, however, it is common to find an old person initiating greetings using the usual response terms, railege / railota 'have you slept well / how have you slept' and/or wasibhoota 'how have you been', especially if he/she realizes that the young person has forgotten his/her greeting responsibility or is deliberately intending to deny him/her of the greeting. If this happens, the young person readily replies sura or sura mzee / mkaire 'good morning or good morning old man/woman; and/or mwasibha or mwasibha mzee / mkaire 'have you been well or have you been well old man/woman; or wasibhoota / wasibhoota mzee / mkaire "how have you been/how have you been old man/woman'. In Kisubi, the tendency for old people to initiate greetings is called (o)kutangirila 'to initiate first'. Generally, old people are noticeably reversing the greeting pattern and it is almost ritualized.

\subsection{Kinship-specific verbal greetings, address forms and paralinguistic behaviours between interlocutors in the Subi community}

\subsubsection{Greetings between parents and children}

In the past years, children were supposed to great their parents even if they slept in the same house. Regardless of the gender, each child was supposed to initiate greetings by saying sura taata 'good morning father' or sura maaha 'good morning mother', and the response was railege / railota 'have you slept well / how have you slept'. If they left the compound and returned in the afternoon, they had to greet their parents mwasibha taata 'have you been well father' or mwasibha maaha 'have you been well mother'. If it was in the evening, the greeting was wasibhoota taata or wasibhoota maaha 'how have you been father/how have you been mother'. For girls, they were supposed to squat. Things have now changed as it is subsequently detailed:

Firstly, very few children are greeting their parents upon waking up in the morning unless they have slept in different houses. This is 
at variance with what Elegbeleye (2005) observes in the Yoruba society where children have to greet their parents even if they have slept in the same house.

Secondly, if it happens that children have slept in a separate house and are still schooling, they simply wake up and rush to school without greeting their parents unless their parents have already woken up and are outside. Or if children have got problems and they want to address them to their parents before leaving, they have to draw the attention of their parents by calling or knocking at the door of their room. After being responded to, the first thing is to greet them sura tata / sura maaha 'good morning father/good morning mother' and each parent in turn responds railege / railota 'have you slept well / how have you slept'; then, they start directing their problems to the responsible parent - usually their father (in patriarchal societies). Since the target is their father, in greetings, their mother can be skipped.

Thirdly, the honorifics taata 'father' and maaha 'mother' are seldom added to the normal greeting terms: the greeters do provide the socalled "dry/plain greetings". This is in concomitant with what is happening in the Hausa society. According to Yusuf (1973) as cited by Oumarou (1997), the honorifics mallan or mallama 'sir/madam' are relatively becoming obsolete.

Fourthly, girls under normal circumstances do rarely squat; they simply genuflect on one knee. Their squatting is contextually motivated; for example, if they are married and have to pay their parents a visit, upon arrival, they normally squat or genuflect on both knees when greeting their parents. Moreover, squatting is manifested more often than not when girls are greeting visitors of either gender especially when they are seated. If they are upright, a deep genuflection on one knee is applied.

For what has been seen in $\$ 4.3 .1$, there is no doubt that some greeting elements in the Subi community have begun decaying partly due to the fact that majority of the parents have loosened their strictness in upholding certain socio-cultural values; hence, children take this as a loophole of beginning to tamper with the greeting system. 


\subsubsection{Greetings between husbands and wives}

Wives do not greet their husbands in the morning if they have been together in the same bed over the night. This is in contrast with what Elegbeleye (2005) observes in the Yoruba society where wives should greet their husbands even if they have slept together in the same bed. Similarly, in the Subi community, if the man leaves the compound to somewhere else and returns back in the past morning hours, his wife should greet him using the past morning greeting terms mwasibha 'have you been well' (in the afternoon) or wasibhoota 'how have you been' (from evening through bed time), and the man replies wasibhoota 'how have you been'. They never embrace each other or handshake, but traditionally well trained wives should squat or genuflect when greeting their husbands. For the less trained women and those who have been trained but do not respect their husbands, they simply genuflect in a superficial way so that they may sustain good relationship with their husbands.

If a man has been on journey, upon arrival, his wife is supposed to greet him sura 'good morning' accompanied with squatting or a deep genuflection on both knees (if the husband is seated), and the husband replies railota 'how have you slept'. If the husband is upright, his wife should deeply genuflect on one knee. Today, traditionally trained wives are enumerable; typical squatting and genuflecting are characteristic of few women. However, it is worth noting that the greeting in this regard is contextually motivated. The use of sura is not confined to a certain temporal chunk; it may be applied at any time provided that the interlocutors have not yet met since morning or for a day or some days, weeks, months, or years.

\subsubsection{Greetings between brothers and sisters}

In the Subi community, sisters greet their brothers first by saying sura (mnyanyazi / kaka) 'good morning (brother)' if it is in the morning or at any time of their encounter on condition that one of the interlocutors has been away for some days. Then, the greetee replies railota 'how 
have you slept'. The honorific or deferential word, mnyanyazi / kaka 'brother', is optionally attached to the actual greeting term.

In the afternoon, the sister greets her brother mwasibha 'have you been well' and he replies wasibhoota 'how have you been'; but from evening through bed time, they greet each other wasibhoota 'how have you been'. While performing the greeting event, sisters should squat or genuflect on both knees or on one knee. This is culturally mandatory and it is usually stressed that sisters should respect their brothers. This is due to the fact that, if the head of the household (father) dies, an elder son is usually enthroned to take care of his young brothers and sisters, as well as his mother. So, if sisters want to be married, their brothers in consultation with their uncles or other respectable elders in the village are the ones who do negotiate dowry. Hence, brothers headed by their elder brother are responsible for marrying off their sisters.

Another interesting issue is that all brothers irrespective of their age should be greeted by their sisters while squatting and/or genuflecting. In the Subi community, it is insisted that women's age does not matter in greeting their brothers. Even if a woman has 40 years or so and her brother has 10 years or so, she is supposed to greet him while squatting or genuflecting. However, a socio-cultural paradigm shift is noticeably underway. Firstly, nowadays, older sisters are reluctant in greeting their young brothers; and if it happens that they greet them, the greeting comes out "between teeth", optionally followed by a superficial genuflection but on one knee. Sometimes, there is no genuflection, and squatting is completely not thought of. And secondly, young brothers are hesitatingly starting to greet their older sisters by saying sura 'good morning' and their sisters replying railota 'how have you been'; and the past morning greetings continue as usual. In other families, the tendency for young brothers to greet their older sisters first using the ritualized greeting terms has been routinized.

\subsubsection{Greetings between sons-in-law and parents-in-law}

If a son-in-law meets his father-in-law, the former squats and greets the latter surawaitu mzee 'good morning old person' if it is in the 
morning or at any time of their encounter provided that they have not met since morning. If they have met in the morning and they happen to re-encounter during the past morning hours, the usual past morning greetings are uttered. Even if the in-law is riding a bicycle and all of a sudden he meets his father-in-law, he [the in-law] does not think twice: he quickly gets out of the bicycle and squats for a greeting. In all encounters, there is no handshaking or embracing. I have not yet come across an event where an in-law is driving and all of a sudden he meets his father-in-law walking. But a close-to-answer guess is that, the in-law will find a convenient place to park the vehicle and get down. He will walk closer to his father-in-law and squat for a greeting. The next circumstantially dictated event is to lift his father-in-law (if he consents for the lift) to the area or near the area of destination. During the greeting event, the in-law should talk deferentially: should sort out appropriate words to use in the conversation. At all times, the in-law should talk gently with reasonable pauses; talking quickly and loudly is a symbol of disrespect to the father-in-law.

The situation is different when the son-in-law meets the motherin-law. The latter usually finds an alternative route to take so that they may not meet physically. However, the mother-in-law does not go far; she stands somewhere and waits for the greeting event to take place. Then, the in-law squats and greets sura mkaire 'good morning old woman'. The honorific mkaire literally refers to an old woman, but in this case, it means more than that: it carries some significant deferential elements. If it happens they meet in an open space, the mother-in-law should maintain a reasonable spatial distance and refrain from eye contact with her in-law. However, the nature of interaction between the son-in-law and his parents-in-law in Kisubi is somehow different from that of the Hausa. According to Oumarou (1997), both father- and mother-in-law in the Hausa community have to change the direction of their route upon meeting their in-law. Moreover, in the interactional discourse, the in-law should keep a reasonable spatial distance with his parents-in-law. In the Subi community, it is the mother-in-law who changes the direction of her route upon meeting her in-law. In terms 
of keeping spatial distance, the situation is similar in both speech communities.

4.3.5. Greetings between daughters-in-law and parents-in-law

Daughters-in-law usually initiate greetings by saying sura (taata / mzee) 'good morning (father/old man)' and the father-in-law replies railota 'how have you slept'. The daughter-in-law, while dressed appropriately in below-knees loose non-transparent clothes, should squat or deeply genuflect on both knees and utter the greeting. When performing the greeting event, she should avoid eye contact with her father-in-law by lowering down her eyes. However, the father-in-law may tactically look at her to see if she is performing the greeting event perfectly. Also, during greeting the father-in-law may take time to diagnose some observable ill-elements in his in-law. For example, if she has dressed inappropriately; if she unblinkly casts eyes to her father-in-law; and if her face displays contemplative behaviour like unnecessary twisting of lips, biting lips, and other awkward mannerisms. During past morning hours, past morning greetings (mwasibha 'have you been well' and wasibhoota 'how have you been') continue as usual. Handshaking and embracing are strictly forbidden between the interlocutors, and a reasonable spatial distance should be maintained.

If the encounter is between the daughter-in-law and her mother-inlaw, the former greets the latter first. The in-law, while squatting or genuflecting on both knees, utters sura (maaha) 'good morning (mother)' and her mother-in-law replies railota 'how have you slept'. Spatial distance between the interlocutors is usually negligible; no handshaking and embracing. From afternoon through evening to bed time, past morning greetings are uttered.

Generally, the greeting event between daughters-in-law and their parents-in-law is performed in a highly disciplined manner. In some families in the Subi community, especially those with low exposure to formal education and townism, parents are still having power over their married sons; they can compel their sons to expel their wives if they consistently over-look the greeting norms, something which is con- 
sidered a sign of contempt and socio-cultural recklessness. However, the expulsion can be effected, though this rarely happens, only when the sons cannot stand on their own, or when they are obediently taking into account whatever they are told by their parents, or when there are other mistakes/misbehaviors consistently committed by their wives.

\section{Conclusion}

On the basis of the findings of this study, it can be deduced that in the Subi community, every chunk of time (i.e. morning, afternoon and evening) has got its own greeting; and the greeting event is performed variably depending on age, gender, kinship relation and context. Moreover, it was learnt that the response greeting terms are somewhat interrogative expressions, i.e. they exhibit the syntax of interrogative constructions, but they are in actual fact uttered affirmatively - without demanding a question mark and subsequent response. However, it was noted that the canonical age-specific afternoon greeting mwasibha is in many occasions - replaced by the evening greeting wasibhoota since the latter is considered a neutral greeting term. Along the same vein, the use of honorific/deferential terms is gradually declining.

The bottom-line argument is that greeting is an indispensable sociocultural apparatus which builds cohesive social relations in any human community. If appropriately and routinely performed, it may have socio-cultural and economic implications. For example, in most human communities, a person who greets appropriately and routinely is considered to have good manners and/or discipline, and this can enable $\mathrm{him} /$ her build good social relations which may earn him/her a very good social capital - which may guarantee him/her easy access to a variety of information, be it social, political, or economic.

\section{References}

Akindele, Dele Femi. 2007. Lumela/Lumela: A socio-pragmatic analysis of Sesotho greetings. Nordic Journal of African Studies 16(1). 1-17. 
Brown, Penelope \& Levinson, Stephen C. 1987. Politeness: Universals of language usage. Cambridge: Cambridge University Press.

Elegbeleye, Oluwatoba Samwel. 2005. Value assessment of greeting scripts in the interpersonal disposition of the Yoruba and the Igbo cultures. Studies of Tribes and Tribals 3(1). 21-25.

Emery, Peter G. 2000. Greeting, congratulating and commiserating. Omani Arabic Language, Culture and Curriculum 13(2). 196-217.

Goffman, Erving. 1955. On face-work: An analysis of ritual elements in social interaction, psychiatry. Journal of Interpersonal Relations 18(3). 213-231.

Haugh, Michael. 2013. Im/politeness, social practice and participation order. Journal of Pragmatics 58. 55-72.

Holmes. Janet. 1992. An introduction to sociolinguistics. London - New York: Longman.

Youssouf, Ibrahim A.G. \& Grimshaw, Allen D. \& Bird, Charles S. 1976. Greetings in the desert. American Ethnologist 3. 797-824.

Ide, Sachiko. 1989. Formal forms and discernment: Two neglected aspects of universals of linguistic politeness. Multilingua 8(2). 223-248.

Irvine, Judith T. 1974. Strategies in status manipulation in the Wolof greeting. In Bauman, Richard \& Sherzer, Joel (eds.), The ethnography of speaking, 167-191. Cambridge: Cambridge University Press.

Lakoff, Robin (ed.). 1975. Language and woman's place. New York: Harper and Row.

Laver, John. 1981. Linguistic routines and politeness in greeting and parting. In Coulmas, Florian (ed.), Conversational routines, 289-304. The Hague: Mouton.

Mapunda, Gastor \& Sommer, Gabriele. 2017. When Shikamoo Mama/Baba replaces Tukuwoni Mawu/Dadi: An account of shifting access rituals among the Ngoni of Tanzania. Linguistik Online 84(5). 63-90.

Mills, Sara. 2011. Discursive approaches to politeness and impoliteness. In Kecskes, I. (ed.), Discursive approaches to politeness, 19-56. Berlin, Mouton de Gruyter.

Nkumbulwa, Joseph. 2015. Endangered African proverbs collections. www. afriprov-org. (Accessed on 2020-05-19.)

Odebunmi, Akinola. 2013. Greetings and politeness in doctor-client encounters in Southwestern Nigeria. International Journal of Society, Culture and Language1(1). 101-117. 
Oumarou, Chaibou Elhadji. 1997. Context and meaning: A semiotic interpretation of greetings in Hausa. Folklore Forum 28(2). 31-41.

Rugemalira, Josephat M. \& Muzale, Henry R.T. 2008. Researching and documenting the languages of Tanzania. Language Documentation and Conservation 2(1). 68-108.

Rwakakindo, Ibrahim Domician. 2019. A morphosyntactic and semantic analysis of possessive noun phrases in Kisubi. Dar es Salaam: University of Dar es Salaam. (Ph.D. thesis.)

Schleicher, Yvonne. 2010. Language as the core of cross-cultural understanding. Paper presented at OSD/AFRICOM Round Table on African Languages and Cultures (Kelly Barracks, Stuttgart, Germany, June 22$23,2010)$.

Schottman, Wendy. 1995. The daily ritual of greeting among the Baatombu of Benin. Anthropological Linguistics 37(4). 487-523.

Sommer, Gabriele \& Lupapula, Abel. 2012. Comparing address forms and systems: Some examples from Bantu. In Marlo, Michael R., et al. (eds.), Selected Proceedings of the $42^{\text {nd }}$ Annual Conference on African Linguistics, 266-277. Somerville, MA: Bayreuth University and University of St. Augustine (Mwanza).

Weinrich, Harald. 1982. Textgrammatik der FranzösischenSprache. Stuttgart: Klett.

Yusuf, Ahmed Beita. 1973. Hausa verbal honorifics: A case study in sociolinguistics. Savana 2(2). 227-230.

Yusuf, Ahmed Beita. 1979. Modes of address among the Kano Hausa: Case study in sociolinguistics. Kano Studies (new Series) 1(4). 100-109.

Received 21.01.2020. Received in revised form 22.05.2020. Accepted 16.10.2020 